\title{
Effect of dimethylmaleate and phorone on glutathione content of Setaria cervi (Nematoda: Filarioidea) during in vitro incubation
}

\author{
S. GUPTA ${ }^{1}$, N. BANU ${ }^{2}$, A. K. SRIVASTAVA ${ }^{1 *}$ \\ ${ }^{1}$ Division of Biochemistry, Central Drug Research Institute, Lucknow 226 001, India, E mail: drarv1955@yahoo.com; \\ ${ }^{2}$ Department of Biochemistry, Faculty of Life Sciences, Aligarh Muslim University, Aligarh 202 002, India
}

\begin{abstract}
Summary
Glutathione metabolism represents a prospective target for antifilarial drug design, and therefore, the alterations in glutathione (GSH) content of filarial worms by known mammalian GSH depletors i.e. dimethylmaleate (DMM) and phorone were first thought for investigation in model filarial worms Setaria cervi. The dose dependent GSH depletion was achieved when these worms were incubated at $37^{\circ} \mathrm{C}$ for $6 \mathrm{~h}$ in Hanks balanced salt solution with varying concentrations $(10-250 \mu \mathrm{M})$ of DMM or phorone. During the short incubation period of $6 \mathrm{~h}, 250 \mu \mathrm{M}$ of DMM and phorone declined more than $90 \%$ of the GSH content of filarial worms.
\end{abstract}

Key words: glutathione; dimethyl maleate; phorone; $S$. cervi; filariasis

\section{Introduction}

Glutathione (GSH) is an important tripeptide with antioxidant and detoxification properties (Meister \& Anderson, 1983). It is a ubiquitous intracellular thiol and has also been detected in a number of filarial species (Singh et al., 1997; Gupta et al., 2002). Filariids have an active GSHlinked antioxidant metabolism to prevent them from the oxidative stress created by the host's immune cells (Rzepczyk \& Bishop, 1984; Schirmer et al., 1987; Selkirk et al., 1998) and as one of the main reasons for their long term endurance within the host body. Glutathione thus is very important for the survival of filarial parasites and any metabolic environment that can lead to its depletion in filarial worms can be harnessed for their elimination from the host body.

There exist three approaches to deplete cells of GSH. Firstly, GSH can be directly complexed to an electrophilic agent via the GSH-S-transferase reaction (Boyland \&
Chasseaud, 1967); secondly, by subjecting the cells to oxidative stress (Jenkinson et al., 1988) and thirdly, by inhibition of its synthesis (Griffith \& Meister, 1979). In present study, the first approach has been taken for GSH depletion. DMM and phorone have been taken as the electrophilic agents (Figs 1 and 2). They are the standard mammalian GSH depletors. However, their effect on filarial parasites is largely unknown. With the aim to get leads for the synthesis of new classes of antifilarial drugs, the effect of these compounds on GSH content of bovine filariids $S$. cervi was investigated in the present studies.<smiles>COC=CC(=O)OC</smiles>

Fig. 1. Dimethylmaleate<smiles>CC(C)=CC=C(C)C</smiles>

Fig. 2. Phorone

\section{Materials and Methods}

Abbreviations

GSH - reduced glutathione; RP-HPLC - reversed phasehigh performance liquid chromatography; DMM - dimethyl maleate; OPA - o-phthalaldehyde; HBSS - Hanks balanced salt solution; S. cervi, Setaria cervi 


\section{Experimental models}

Adult bovine $S$. cervi worms which represent a convenient model for filarial nematodes were collected from the peritoneal cavity of naturally infected freshly slaughtered water buffaloes (Bubalus bubalis Linn) at a local abbatoir and brought to the laboratory in Ringer's saline.

\section{Chemicals}

GSH, OPA, DMM and phorone were purchased from Sigma, USA. HBSS, gentamycin, streptomycin sulphate and penicillin $\mathrm{G}$ were obtained from Hi Media Laboratories, India. Methanol (HPLC grade) and sodium acetate used were from Merck, India. All other chemicals used were of analytical grade.

\section{Instrumentation}

RP-HPLC was performed using Waters Millennium ${ }^{\circledR 2}$ chromatography management system which includes Waters 474 scanning fluorescence detector, Waters 515 HPLC pumps and chromatographic data acquisition and processsing computer with Millennium ${ }^{32}$ chromatography manager software. Reversed phase analytical Spherisorb S5 ODS2 (4.0 mm x $125 \mathrm{~mm}$ ) column, S5 ODS2 (4.6 mm x $10 \mathrm{~mm}$ ) guard cartridges and accessories were also purchased from Waters (Waters Corporation, Milford, Massachusetts).

\section{Experimental procedure}

Actively moving $S$. cervi adult female worms, after being washed with autoclaved saline $(0.9 \% \mathrm{NaCl})$ were allowed to revive for $1 \mathrm{~h}$ in HBSS containing $1 \mu \mathrm{g} / \mathrm{ml}$ gentamycin at $37^{\circ} \mathrm{C}$ in Dubnoff metabolic shaker. To maintain the $\mathrm{pH}$ in the range of $7.2-7.4$, sodium bicarbonate was constantly added to the medium during revival time. After revival, three fully motile parasites were transferred per conical flask containing $25 \mathrm{ml}$ of HBSS (pH 7.2 - 7.4) supplemented with $5 \mathrm{mM}$ glucose, $100 \mu \mathrm{g} / \mathrm{ml}$ streptomycin sulphate and 300 units $/ \mathrm{ml}$ penicillin G. DMM and phorone were added at varying concentrations $(10-250 \mu \mathrm{M})$, respectively. Controls were run in parallel. The flasks were incubated at $37^{\circ} \mathrm{C}$ in Dubnoff metabolic shaker for $6 \mathrm{~h}$ at low speed. After incubation, the worms were removed from the flask and washed thoroughly with ice cold saline. A $5 \%$ homogenate $(\mathrm{w} / \mathrm{v})$ was prepared in $2.5 \%$ sulphosalicylic acid and was centrifuged at $10,000 \mathrm{~g}$ for $10 \mathrm{~min}$. The supernatant was saved and used for GSH analysis.

\section{Analytical procedure for GSH estimation}

GSH was determined by RP-HPLC using Spherisorb S5 ODS2 Column $(4.0 \times 125 \mathrm{~mm}) .50 \mu \mathrm{l}$ aliquots of the $10,000 \mathrm{~g}$ supernatant were mixed with $50 \mu \mathrm{l}$ of OPA reagent and the reaction was stopped after 1 min with $100 \mu \mathrm{l}$ of $0.1 \mathrm{M}$ potassium phosphate- $\mathrm{H}_{3} \mathrm{PO}_{4}$ buffer $(\mathrm{pH}$ 7.0). The OPA reagent was composed of $40 \mathrm{mM} \mathrm{OPA}$ and $0.4 \mathrm{M}$ sodium tetraborate $(\mathrm{pH} 9.0)$. In all cases, $50 \mu \mathrm{l}$ of derivatised aliquot was subjected to the column for GSH analysis. Separation was performed at a flow rate of $1 \mathrm{ml} / \mathrm{min}$ with solvent $\mathrm{A}(0.15 \mathrm{M}$ sodium acetate, $\mathrm{pH}$ adjusted to 7.0 with acetic acid/methanol (1/24, v/v)) and solvent B (100 $\%$ methanol). Gradient (expressed as percentages of solvent B) used was: $8 \mathrm{~min}, 0 ; 12 \mathrm{~min}, 10 \% ; 13 \mathrm{~min}, 25 \%$; $27 \mathrm{~min}, 90 \%$; $35 \mathrm{~min}, 90 \%$; $40 \mathrm{~min}, 0 \%$; $50 \mathrm{~min}, 0 \%$. Excitation and emission wavelengths were 350 and $420 \mathrm{~nm}$ respectively. GSH in samples was estimated using standard curve for GSH $(0.5-5 \mu \mathrm{g} / \mathrm{ml})$. The mentioned procedure is as described by Hussain and Walter (1996). The sensitivity of the used RP-HPLC method is down to the level of picomoles (Neuschwander-Tetri \& Roll, 1989) where as sensitivity of spectrofluorometric method used in previous studies for GSH estimation was down to the level of micromoles only (Hissin \& Hilf, 1976).

\section{Statistical analysis}

Data is expressed as mean $\pm \mathrm{S}$ D. Significance of differentces between means was determined by Student's t-test. Results were obtained in terms of $\mathrm{mg} \mathrm{GSH} /$ g-wet weight parasite based upon triplicate determinations.

\section{Results}

Under the specified analytical conditions GSH content in the crude homogenates of adult $S$. cervi worms was determined to be around $0.048 \pm 0.009 \mathrm{mg} \mathrm{GSH} / \mathrm{g}$ wet weight by RP-HPLC method. Fig. 3 is representing the chromatographic profile for GSH estimation where retention time was observed at $9.2 \mathrm{~min}$.

Fig. 4 demonstrates the effect of various concentrations of DMM $(10 \mu \mathrm{M}$ to $250 \mu \mathrm{M})$ on GSH content of $S$. cervi females. DMM depleted GSH in a dose-dependent manner. DMM concentration of 10,50 and $250 \mu \mathrm{M}$ depleted around 22,38 and $95 \%$ of GSH respectively, after incubation of the worms for $6 \mathrm{~h}$ at $37^{\circ} \mathrm{C}$.

As shown in Fig. 5, phorone also depleted the GSH levels of $S$. cervi in a dose-dependent manner as 10, 50, and 250 $\mu \mathrm{M}$ phorone depleted 50, 79 and $93 \%$ of GSH respectively, after incubation of worms for $6 \mathrm{~h}$ at $37^{\circ} \mathrm{C}$.

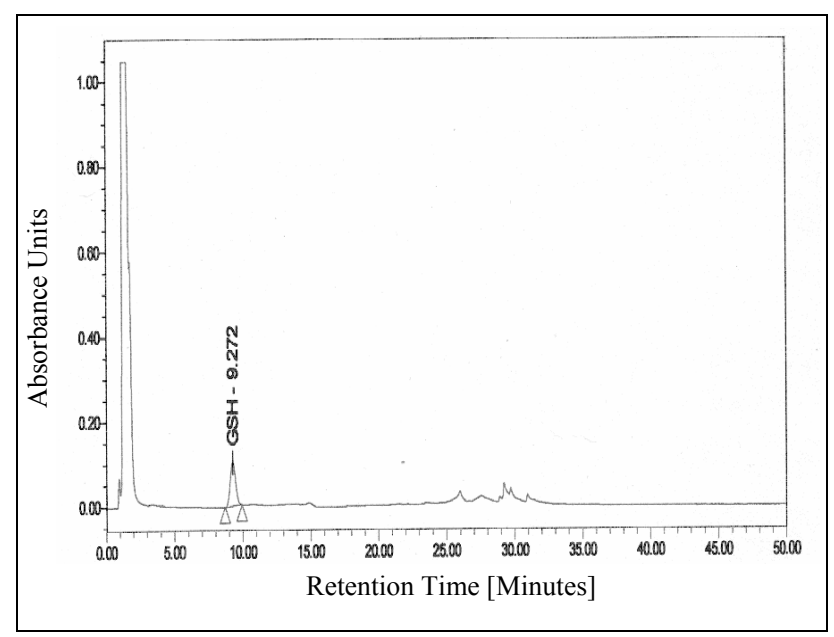

Fig. 3. Chromatographic profile for GSH estimation 


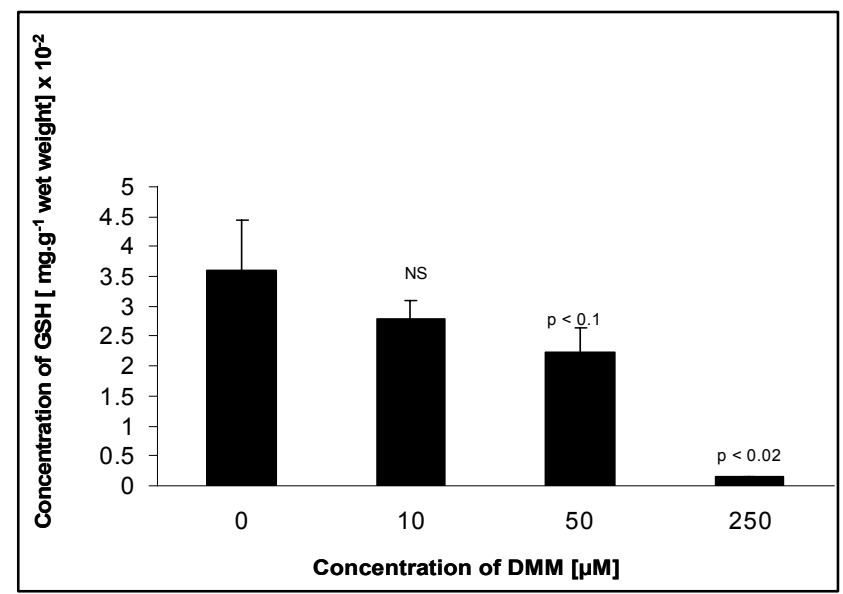

Fig. 4. Effect of dimethylmaleate (DMM) on GSH content in Setaria cervi

Depletion of GSH in $S$. cervi was estimated after in vitro incubation of adult female filarial worms $(\mathrm{n}=3)$ in $25 \mathrm{ml}$ HBSS medium noctaining varying dimethylmaleate (DMM) concentrations $(10-250$ $\mu \mathrm{M})$ at $37^{\circ} \mathrm{C}$ for $6 \mathrm{~h}$. The findings are represented in terms of $\mathrm{mg}$ $\mathrm{GSH} / \mathrm{g}$ wet weight parasite and represent mean values for three independent experiments. NS denotes non significant

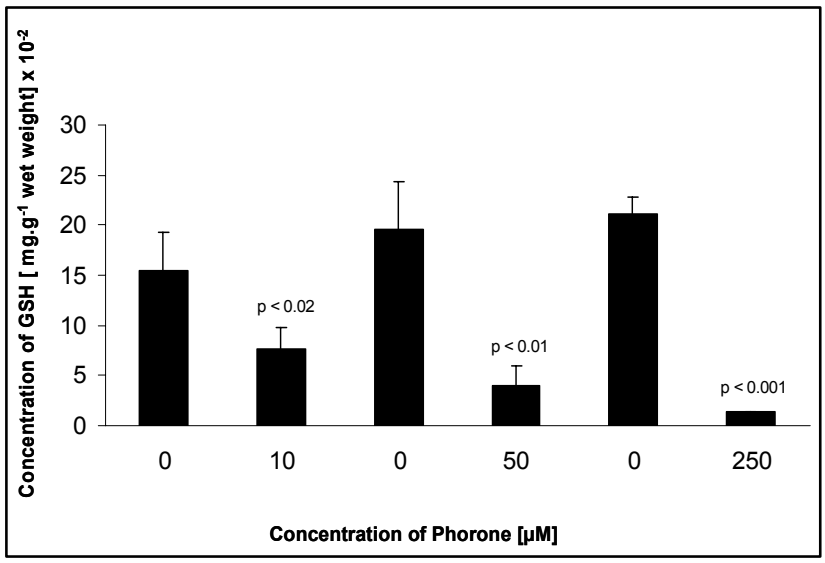

Fig. 5. Effect of phorone on GSH content in Setaria cervi

GSH levels were measured after in vitro treatment of $S$. cervi adult females with phorone. The worms $(n=3)$ were maintained in $25 \mathrm{ml}$ HBSS medium at $37^{\circ} \mathrm{C}$ for $6 \mathrm{~h}$ with $10 \mu \mathrm{M}, 50 \mu \mathrm{M}$ and $250 \mu \mathrm{M}$ phorone concentration, respectively. As phorone was dissolved in dimethyl sulfoxide (DMSO), three sets of control were taken containing varying amounts of DMSO equal to that present in treated ones. The findings are represented in terms of $\mathrm{mg} \mathrm{GSH} / \mathrm{g}$ wet weight parasite and represent mean values for three independent experiments

\section{Discussion}

Glutathione depletion may be useful in chemotherapeutic situations in which the cells to be killed and the cells to be spared have substantially different quantitative requirements for GSH. Most mammalian host cells have a large excess of GSH but parasites often have levels close to those required for survival (Meister, 1988). GSH depletion, thus, might be more harmful to parasites than to the normal tissues of the host organisms.

DMM and phorone (2, 6-Dimethyl-2, 5-heptadien-4-one) are $\alpha, \beta$ - unsaturated compounds that form conjugate with GSH (Boyland \& Chasseaud, 1967; Richardson \& Murphy, 1975; Younes \& Siegers, 1980; Wirth \& Thorgeirsson, 1978; Barnhart \& Combes, 1978; van Doorn et al., 1978). The reaction involves the addition of the sulfhydryl group of GSH to the activated double bond of these compounds (Fig. 6). Various $\alpha, \beta$ - unsaturated compounds have been extensively studied for their in vitro and in vivo GSH depletion potential (Plummer et al., 1981). These are typical weak electrophiles that react with GSH in the presence of the GSH-S-transferase (Boyland \& Chasseaud, 1967). In present study, these compounds have given remarkable results in terms of GSH depletion in filarial worms. Such class of compounds are good leads for the synthesis of anti-filarial drugs.
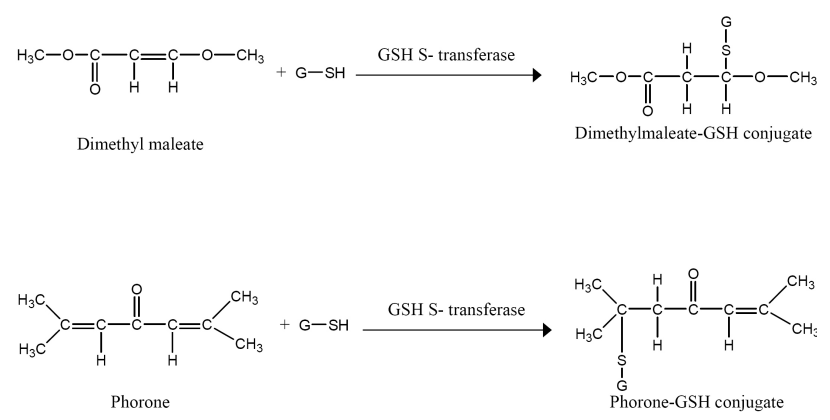

Fig. 6. Conjugation of DMM and phorone with glutathione

For studies concerning the effect of decreased glutathione availability on drug metabolism or on the toxicity of a certain compound, it is imperative that the agent used to deplete cellular GSH does not interfere with the metabolic disposition or the bioactivation systems involved. Such interference has been reported in the case of diethylmaleate (DEM), the higher member of the homologous series of DMM (Anders, 1978). No studies have been done at present to study the effect of DMM on GSH content as well as on other systems. Present study is an attempt in this direction. In this context, phorone is highly appreciable as treatment of rats with phorone had no influence on such systems even at the time of maximal GSH depletion. Cytochrome P-450 content, NADPH-cytochrome c reductase activity, aminopyrine demethylation capacity, as well as the production of $\mathrm{O}_{2}{ }^{-}$and $\mathrm{H}_{2} \mathrm{O}_{2}$ were unaffected by phorone treatment (Younes et al., 1986). Phorone treatment also had no effect on lipid peroxidation, glutathione peroxidase and superoxide dismutase activity, thus this agent seems to be a valuable tool as it merely leads to glutathione depletion (Mehmetcik et al., 1997).

\section{Acknowledgements}

Financial assistance in the form of Senior Research Fellowship to one of our authors (SG) from CSIR, New Delhi 
(India) and Volkswagen Stiftung, Hannover (Germany) in the form of ad-hoc research grant to AKS for carrying out this research is highly acknowledged.

\section{References}

ANDERS, M. W. (1978): Inhibition and enhancement of microsomal drug metabolism by diethylmaleate. Biochem. Pharmacol., 27: 1098 - 1101

BARnhart, J. L., ComBes, B. (1978): Choleresis associated with metabolism and biliary excretion of diethylmaleate in the rat and dog. J. Pharmacol. Exp. Ther., 206: 614 $-623$

Boyland, E., Chasseaud, L. F. (1967): Enzyme-catalysed conjugations of glutathione with unsaturated compounds. Biochem. J., 104: 95 - 102

Griffith, O. W., Meister, A. (1979): Potent and specific inhibition of glutathione synthesis by buthionine sulfoximine (S-n-butyl homocysteine sulfoximine). J. Biol. Chem., 254: 7558 - 7560

Gupta, S., Tripathi, R., Srivastava, A. K., Iqbal, J. (2002): Depletion of intracellular glutathione of Setaria cervi by buthionine sulfoximine, carmustine and their analogues. In Callaos, N., He, Y., Perez-Perez, J. A. (Eds): Proceedings of International Institute on Systemics and Informatics (IIIS) and International Federation of Systems Research (IFSR), 17: 491 - 496

Hissin, P. J., HILF, R. (1976): A fluorometric method for determination of oxidized and reduced glutathione in tissues. Anal. Biochem., 74: $214-226$

HuSSAIN, A. S., WALTER, R. D. (1996): Inhibition of glutathione synthesis of Ascaris sunn by buthionine sulfoximine. Parasitol. Res., 82: $372-374$

JENKInSON, S. G., JoRdAN, J. M., LAWREnCE, R. A. (1988): BCNU induced protein from hyperbaric hyperoxia: role of glutathione metabolism. J. Appl. Physiol., 65: 2531 - 2536 Mehmetcik, G., Alptekin, N., Toker, G., Uysal, M. (1997): Mitochondrial lipid peroxides and antioxidant enzymes in the liver following phorone-induced glutathione depletion. Res. Commun. Mol. Pathol. Pharmacol., 96: 353 $-356$

MeISTER, A. (1988): Glutathione metabolism and its selec- tive modification. J. Biol. Chem., 263: $17205-17208$

Meister, A., Anderson, M. E. (1983): Glutathione. Annu. Rev. Biochem., 52: $711-760$

Neuschwander-Tetri, B. A., Roll, F. J. (1989): Glutathione measurement by high performance liquid chromatography separation and fluorescence detection of the glutathione-orthophthalaldehyde adduct. Anal. Biochem., 179: $236-241$

Plummer, J. L., Sies, B.R., Bend, J. R. (1981): Chemical depletion of glutathione in vivo. Methods Enzymol., 77: 50 $-59$

RICHARDSON, R. J., MURPHY, S. D. (1975): Effect of glutathione depletion on tissue deposition of methylmercury in rats. Appl. Pharmacol., 31: 505 - 519

RZEPCZYK, C. M., BISHOP, C. J. (1984): Immunological and ultrastructural aspects of the cell-mediated killing of D. immitis microfilariae. Parasit. Immunol., 6: 443 - 457

SChirmer, R. H., SChOllhammer, T., Eisenbrand, G., KRAUTH-SIEGEL, R. L (1987): Oxidative stress as a defence mechanism against parasitic infections. Free Radic. Res. Commun., 3: 3 - 12

Selkirk, M. E., Smith, V. P., Thomas, G. R., Gounaris, K. (1998): Resistance of filarial nematode parasites to oxidative stress. Int. J. Parasitol., 28: 1315 - 1332

Singh, S. N., Srivastava, A. K., Chatterjee, R. K. (1997): Presence of glutathione, glutathione reductase and glutathione peroxidase in filarial parasites. Helminthologia, 34: $70-73$

VAN DOORN, R., LEIJDEKKERS, C. M., HENDERSON, P. T. (1978): Synergistic effects of phorone on the hepatotoxicity of bromobenzene and paracetamol in mice. Toxicology, 11: $225-233$

WirTh, P. J., Thorgeirsson, S. S. (1978): Glutathione synthesis and degradation in fetal and adult rat liver and Navikoff hepatoma. Cancer Res., 38: 2861 - 2865

Younes, M., Sharma, S. C., Siegers, C. P. (1986): Glutathione depletion by phorone: organ specificity and effect on hepatic microsomal mixed-function oxidase system. Drug Chem. Toxicol., 9: $67-73$

Younes, M., SIEGERS, C. P. (1980): Lipid peroxidation as a consequence of glutathione depletion in rat and mouse liver. Pharmacol., 27: $119-128$ 